\title{
Epidemiology of measles outbreaks in Qatar in 2007
}

M.G. Al-Kuwari, ${ }^{1}$ Z.A. Nazzal' ${ }^{1}$ and A.A. Al Khenji ${ }^{7}$

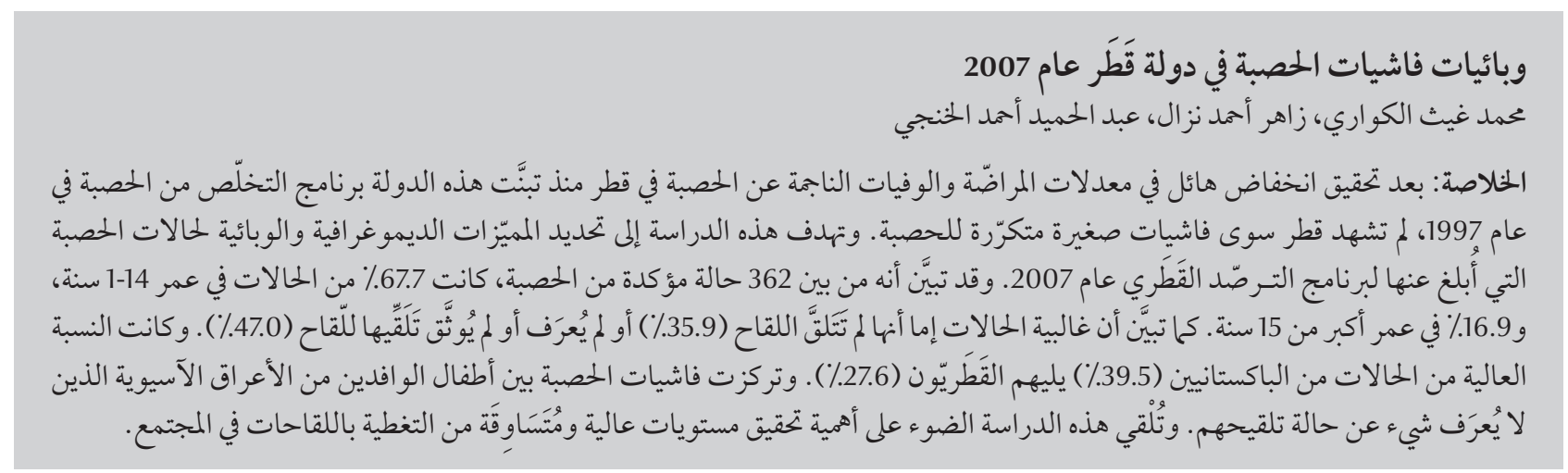

ABSTRACT While a major reduction in morbidity and mortality from measles has been achieved in Qatar since it adopted the measles elimination programme in 1997, the country has experienced small, recurrent measles outbreaks. The aim of this study was to determine the demographical and epidemiological characteristics of measles cases reported to the surveillance programme in Qatar in 2007. Of 362 confirmed cases 67.7\% were among children aged $1-14$ years old and $16.9 \%$ were $>15$ years. A majority of cases were unvaccinated (35.9\%) or had unknown or undocumented vaccination status (47.0\%). The high proportion of cases were among Pakistani nationals (39.5\%) followed by Qataris (27.6\%). Measles outbreaks were concentrated among the children of expatriates of Asian ethnicity with unknown vaccination status. This highlights the importance of achieving uniformly high levels of vaccination coverage in a community.

\section{Épidémiologie des flambées de rougeole au Qatar en 2007}

RÉSUMÉ Alors qu'une baisse importante de la morbidité et de la mortalité dues à la rougeole avait été obtenue au Qatar depuis I'adoption du programme d'élimination de la rougeole en 1997, le pays a connu des petites flambées récurrentes de rougeole. La présente étude visait à déterminer les caractéristiques démographiques et épidémiologiques des cas de rougeole rapportés dans le cadre du programme de surveillance au Qatar en 2007. Sur les 362 cas confirmés, 67,7 \% concernaient des enfants âgés de 1 à 14 ans et 16,9\% avaient plus de 15 ans. La majorité des cas n'avait pas été vaccinée (35,9\%) ou leur statut vaccinal était inconnu ou non documenté (47,0 \%). Les enfants de nationalité pakistanaise représentaient une forte proportion des cas (39,5\%), suivis par les enfants de nationalité qatarie (27,6\%). Les flambées de rougeole étaient concentrées chez des enfants d'expatriés appartenant au groupe ethnique asiatique et au statut vaccinal inconnu. Ces résultats soulignent l'importance d'atteindre des taux de couverture vaccinale élevés et uniformes dans une communauté. 


\section{Introduction}

Measles is a highly infectious vaccinepreventable disease caused by the measles virus and characterized by a high potential to produce outbreaks [1]. For a time it was one of the leading causes of childhood death, especially in developing countries [2]. It is estimated that before the implementation of measles elimination activities there were 100000 deaths each year due to measles in the Eastern Mediterranean Region (EMR) [3].

Qatar has committed to the World Health Organization (WHO) regional initiative "eliminate measles virus transmission in EMR by 2010" using the following strategies: strengthening routine infant immunization, giving a second opportunity for measles immunization, and strengthening measles surveillance [3,4]. Children in Qatar are given the first dose of the measles/ mumps/rubella (MMR) vaccine at 1 year of age and the second dose at 4-6 years of age. Failure to deliver at least 1 dose of measles vaccine to all infants remains the primary reason for the high rates of mortality and morbidity from measles in developing countries [5]. A significant reduction in the morbidity and mortality of measles in Qatar has been achieved since 1997 when the country adopted the measles elimination programme. Nevertheless, Qatar has experienced recurrent, small-scale measles outbreaks, increasing the incidence to about 400 cases / 1000000 for the year 2007 [6].

An understanding of the basic epidemiology of measles is a prerequisite for effective control measures [7]. It is recommended by WHO to collect adequate surveillance data on measles cases and outbreaks and analyse these data to allow further evaluation of vaccination coverage as well as the implementation of the appropriate preventive measures needed to control and prevent measles [8]. The aim of this study therefore was to determine the demographic and epidemiological characteristics of measles cases in Qatar in 2007 in order to inform public health strategies to improve measles control in the country.

\section{Methods}

This study was conducted in the Gulf country of Qatar (estimated population $>1500000$ in 2008). A retrospective review of records of measles notification forms available within the national epidemiological surveillance system was carried out from 1 January to 31 December 2007. Data were collected on all measles cases reported to the measles surveillance system of the public health department of the National Health Authority in Qatar during the year 2007.

All 362 cases notified by the attending physicians during this period were included in the study. Information was collected using a specially designed checklist that included: patient's demographic data (age, sex, nationality), MMR vaccination status, place of reporting and time of reporting the case by month, and laboratory data.

The clinical case definition used was as following: a patient displaying maculopapular rash, fever $\geq 38.3^{\circ} \mathrm{C}$ and cough, coryza or conjunctivitis. Cases were classified as clinical (if they fulfilled the clinical definition), confirmed (if measles-specific IgM antibodies were present in a blood sample collected within 3-28 days of the onset of rash) or as epidemiologically linked (if the suspected case had been in contact with a confirmed case within the incubation period).

The data were analysed using SPSS, version 11.0. Descriptive statistics and the chi-squared test were used for analysis.

\section{Results}

In 2007, 362 cases of measles were notified from all the health care sectors in Qatar. The peak of the outbreaks was in late spring and early summer, with 207 cases (57.2\%) reported during May and June (Figure 1).

Diagnosis of measles was laboratory confirmed in 124 (34.3\%) cases, while $13(3.6 \%)$ cases were classified as epidemiologically linked and 224 (61.9\%) were clinically confirmed cases.

Table 1 shows the demographic characteristics of the reported measles cases; 192 cases (53.0\%) were among males. In term of age, the median age was 5 years (range, 2 months to 52 years).

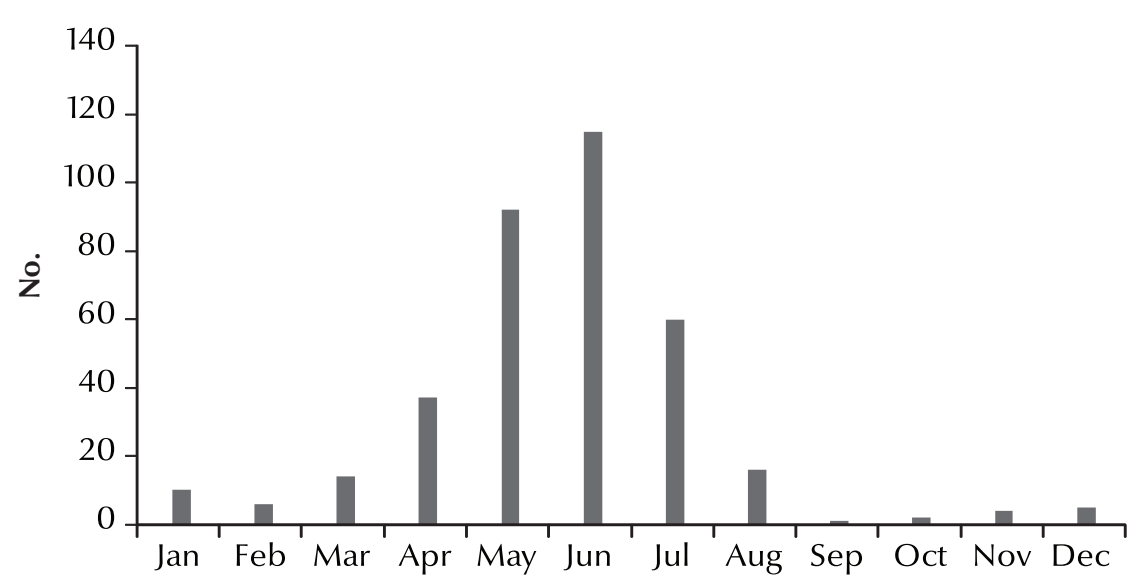

Month

Figure 1 Monthly frequency of reported measles cases in Qatar, 2007 


\begin{tabular}{lcc}
\hline \multicolumn{2}{l}{ Table 1 Characteristics of the reported measles cases in Qatar, $2007(\boldsymbol{n}=362)$} \\
\hline Variable & No. & $\%$ \\
Age group (years) & 56 & 17.1 \\
$<1$ & 121 & 33.4 \\
$1-4$ & 124 & 34.4 \\
$5-14$ & 61 & 16.9 \\
$>15$ & & \\
Sex & 192 & 53.0 \\
Male & 170 & 47.0 \\
Female & & \\
Nationality & 100 & 26.7 \\
Qatari & 143 & 39.5 \\
Pakistani & 30 & 8.3 \\
Indian & 68 & 18.8 \\
Other & & \\
District & 222 & 61.3 \\
Doha & 110 & 29.0 \\
Al Rayyan & 18 & 5.0 \\
Wakra & 12 & 3.3 \\
Al Khor & & \\
\hline
\end{tabular}

The highest proportion of the measles cases was in the age group 5-14 years (34.3\%), followed by ages $1-4$ years (33.4\%); altogether the $1-14$ years age group formed $67.7 \%$ of cases.

On reviewing the vaccination status, it was found that 130 (35.9\%) cases were unvaccinated, $62(17.1 \%)$ were vaccinated and 170 (47.0\%) cases were of unknown vaccination status.

Analysis of nationality showed that $72.4 \%$ were expatriates, with the highest proportion of cases (39.5\%) among
Pakistani nationals, while Qatari nationals represented $27.6 \%$ of cases.

The highest proportion of unvaccinated case was among Pakistani nationals (43.4\%) compared with $35.0 \%$ and $26.7 \%$ among Qataris and Indians respectively (Table 2). However, this difference between nationalities was not statistically significant $\left(\chi^{2}=7.408, \mathrm{df}=6\right.$, $P=0.285)$. Regarding the age group, the great majority of unvaccinated cases (94.6\%) were among children $<1$ years, compared with $13.1 \%$ among cases $>15$ years old. This relation between vaccination status and age group was statistically significant $\left(\chi^{2}=1.207, \mathrm{df}=\right.$ $6, P<0.001)$.

\section{Discussion}

The recurrence of small-scale outbreaks of measles in Qatar is evidence that the potential for local outbreaks is still present despite the increased rate of MMR vaccination coverage for the 1st dose and improved measles surveillance in recent years. This study provides details of the epidemiological characteristics of measles cases re-

\begin{tabular}{|c|c|c|c|c|c|c|c|}
\hline \multirow[t]{3}{*}{ Variable } & \multirow{3}{*}{$\begin{array}{l}\text { Total } \\
\text { No. }\end{array}$} & \multicolumn{6}{|c|}{ Vaccination status } \\
\hline & & \multicolumn{2}{|c|}{ Vaccinated } & \multicolumn{2}{|c|}{ Unvaccinated } & \multicolumn{2}{|c|}{ Unknown } \\
\hline & & No. & $\%$ & No. & $\%$ & No. & $\%$ \\
\hline \multicolumn{8}{|l|}{ Nationality } \\
\hline Qatari & 100 & 18 & 18.0 & 35 & 35.0 & 47 & 47.0 \\
\hline Pakistani & 143 & 23 & 16.1 & 62 & 43.4 & 58 & 40.6 \\
\hline Indian & 30 & 5 & 16.5 & 8 & 26.7 & 17 & 56.7 \\
\hline \multirow[t]{2}{*}{ Other } & 89 & 16 & 18.0 & 25 & 28.1 & 48 & 53.4 \\
\hline & \multicolumn{7}{|c|}{$\chi^{2}=7.408, \mathrm{df}=6, P=0.285$} \\
\hline \multicolumn{8}{|c|}{ Age group (years) } \\
\hline$<1$ & 56 & 2 & 3.6 & 53 & 94.6 & 1 & 1.8 \\
\hline $1-4$ & 121 & 28 & 23.1 & 32 & 26.4 & 61 & 50.4 \\
\hline $5-14$ & 124 & 28 & 22.6 & 37 & 29.8 & 59 & 47.6 \\
\hline \multirow[t]{2}{*}{$>15$} & 61 & 4 & 6.6 & 8 & 13.1 & 49 & 80.3 \\
\hline & \multicolumn{7}{|c|}{$\chi^{2}=1.207, \mathrm{df}=6, P<0.001$} \\
\hline
\end{tabular}

$d f=$ degrees of freedom. 
ported to the public health department in Qatar in 2007.

The peak season for occurrence of measles outbreaks was late spring, April to June. Such a seasonal trend which peaks in late spring and early summer has been reported in another study, in Taiwan [9].

The median age of the cases in our study was 5 years, which is similar to studies conducted in Oman and The Netherlands [10,11]. However, it was younger than found in studies in Saudi Arabia [12] and Oceania [13]. The current study revealed that children aged $1-4$ and 5-14 years were more affected than infants $<1$ year old. This is consistent with the natural history of measles, as infants are protected by their maternal antibodies [14].

In relation to vaccination status, our study revealed that $17.0 \%$ of cases were known to have been vaccinated with MMR and the majority were either unvaccinated or of unknown vaccination status. The proportion of measles cases who had received MMR is low compared with other studies in the region. Studies conducted in Oman, Saudi Arabia, and the Islamic Republic of Iran showed vaccination rates of measles cases of $50 \%, 62 \%$ and $46.5 \%$ respectively $[11,12,15]$. Studies from The Netherlands and Germany showed that only $5 \%-6 \%$ of measles cases were vaccinated $[10,16]$. The high rate of unvaccinated children aged $<1$ year is due to the fact that the MMR 1st dose is usually given at the 1 st birthday.
In agreement with the epidemiological features of measles in other neighbouring countries such as Oman and Saudi Arabia $[11,12]$, more measles cases in Qatar were reported among children of expatriates (about two-thirds of cases) than among Qatari nationals. Almost $40 \%$ of all measles cases were among children of Pakistani nationality, the majority of whom had not received a single dose of MMR ( $43.4 \%$ were unvaccinated). This can be explained by the low socioeconomic status of this community in Qatar, which is likely to be linked to poor health awareness.

The number of MMR doses among those who were vaccinated could not be determined from the data of the surveillance system and as it is known that measles vaccine is highly effective, reaching more than $98 \%$ efficacy if given in 2 doses particularly if given at preschool age [14]. The occurrence of outbreaks from time to time can be attributed to an accumulation of susceptible people over time (those who are unvaccinated and those who received only 1 MMR dose), especially among those who received 1 dose, where the effectiveness of the vaccine reaches only $90 \%$ [14].

The occurrence of measles among those who are immunized with $2 \mathrm{MMR}$ doses raises doubts about the effectiveness of the MMR vaccine in Qatar and points to the possible use of out-of-date vaccine or poor storage and handling of vaccines. Such failure in vaccination has been reported in some Eastern
European countries. For example, in Poland and the Ukraine 41\% and 36\% of reported measles cases had received 2 MMR doses. There are also concerns about the reliability of the immunization registration and this needs to be investigated with an evaluation of the reporting system used by the communicable disease control unit in Qatar. Despite these hypotheses, the occurrence of measles outbreaks from time to time in some developed countries with $>90 \%$ coverage is considered a normal phenomenon [17].

In conclusion, our study showed that the age group most affected with measles in Qatar was 1-14 years, and most of cases were unvaccinated or had unknown vaccination status. To prevent future outbreaks of measles, measles control and vaccination awareness should be continued and improved at all levels. "Catch-up" mass vaccination campaigns should be conducted to interrupt chains of transmission. In addition, surveillance enhancement and maintaining high coverage of the 2 nd dose of MMR is critical to control measles outbreaks in Qatar, especially among the children of the expatriate Asian community. Apart from this, the large proportion of cases of unknown vaccination status highlights the importance of improving the quality of the vaccination registry and improving the data collected during the investigation of future measles outbreaks.

\section{References}

1. Muscat M, Sciberras M. Towards measles elimination. Malta Medical Journal. 2003, 15(2):36-38.

2. Halsey NA. Measles in developing countries. British Medical Journal, 2006, 333:1234.

3. Measles elimination and prevention of congenital rubella syndrome in the Eastern Mediterranean Region. Plan of action 2006-2010. Cairo, World Health Organization. Regional Office for the Eastern Mediterranean, 2006 (http://www.emro. who.int/vpi/measles/media/pdf/measlesplan_2006_2010. pdf, accessed 4 December 2011).

4. Measles elimination field guide, 2nd ed. Washington DC, World Health Organization, Pan American Health Organization, 2005.
5. Measles mortality reduction and regional elimination strategic plan 2001-2005. Geneva, World Health Organization, 2001 (WHO/V\&B/01.13 Rev. 1).

6. Incidence of measles in EMRO, January 1 to December 31 2007, January 1st - July 31st 2008. Measles Monthly Bulletin, July 2008 (http://www.emro.who.int/vpi/measles/media/pdf/ MeaslesBulletin_July08.pdf, accessed 4 December 2011).

7. Clements CJ et al. The epidemiology of measles. World Health Statistics Quarterly, 1992, 45:285-291.

8. Using surveillance data and outbreak investigations to strengthen measles immunization programmes. Geneva, World Health Organization, 1996. 
9. Chen CJ, Lin TM, Yeh YL. Analysis of the secular trend and seasonal variation of measles mortality rate in Taiwan. Annals of the Academy of Medicine, Singapore, 1984, 13:136-141.

10. Van den Hof S, Conyn-van Spaendonck MAE, van Steenbergen JE. Measles epidemic in the Netherlands, 1999-2000. Journal of Infectious Diseases, 2002, 186:1483-1486.

11. Patel PK et al. Measles epidemiology and its implications for a vaccination programme in Oman. Eastern Mediterranean Health Journal, 2008, 14:579-589.

12. Jahan S et al. Measles outbreak in Qassim, Saudi Arabia 2007: epidemiology and evaluation of outbreak response. Journal of Public Health, 2008, 30:384-390.
13. Hyde TB et al. Measles outbreak in the Republic of the Marshall Islands, 2003. International Journal of Epidemiology, 2006, 35(2):299-306

14. Chin J. Control of communicable diseases manual, 17th ed. Washington DC, American Public Health Association, 2000.

15. Saffar MJ et al. Measles epidemiology in Mazandaran province, Iran, 2000-2002. Tropical Doctor 2007, 37(1):30-32.

16. Siedler A et al. Two outbreaks of measles in Germany 2005. Euro Surveillance, 2006, 11:615.

17. Cutts FT, Dabis F. Controle de la rougeole dans les pays en developpement [Measles control in developing countries]. Sante, 1994, 4:163-171.

\section{Measles incidence for 2009 and 2010 in countries of the Eastern Mediterranean Region of WHO (Source: http://www.emro.who.int/vpi/measles/media/pdf/MeaslesBulletin_December10.pdf)}

\begin{tabular}{|c|c|c|c|c|c|}
\hline \multirow[t]{2}{*}{ Country } & \multicolumn{2}{|c|}{$\begin{array}{c}\text { Measles incidence } \\
\text { (cases/million population) }\end{array}$} & \multirow[t]{2}{*}{ Country } & \multicolumn{2}{|c|}{$\begin{array}{c}\text { Measles incidence } \\
\text { (cases/million population) }\end{array}$} \\
\hline & 2009 & 2010 & & 2009 & 2010 \\
\hline Afghanistan & 109.34 & 76.9 & Oman & 5.67 & 0.9 \\
\hline Bahrain & 2.71 & 0.0 & Pakistan & 2.59 & 5.7 \\
\hline Djibouti & 24.45 & 0.0 & Palestine & 1.27 & 0.0 \\
\hline $\operatorname{Iran}(I R)$ & 3.95 & 7.6 & Qatar & 26.24 & 59.8 \\
\hline Iraq & 910.17 & 8.8 & Saudi Arabia & 3.15 & 15.8 \\
\hline Jordan & 0.00 & 0.0 & Somalia & 161.14 & 66.6 \\
\hline Egypt & 3.31 & 0.2 & Sudan & 1.74 & 15.2 \\
\hline Kuwait & 35.44 & 10.4 & $\begin{array}{l}\text { Syrian Arab } \\
\text { Republic }\end{array}$ & 1.79 & 0.4 \\
\hline Lebanon & 7.64 & 4.9 & Tunisia & 0.19 & 0.0 \\
\hline $\begin{array}{l}\text { Libyan Arab } \\
\text { Jamahiriya }\end{array}$ & 58.72 & 9.6 & $\begin{array}{l}\text { United Arab } \\
\text { Emirates }\end{array}$ & 17.63 & 16.2 \\
\hline Morocco & 18.79 & 16.1 & Yemen & 5.51 & 15.5 \\
\hline
\end{tabular}

